\title{
Investigating the reliability and validity of the Social-Emotional Learning Scale in Turkish Form*
}

\author{
Tarkk TOTAN**
}

\author{
Zekavet KABASAKAL ${ }^{* * *}$
}

\begin{abstract}
Aim of this study investigation of reliability and validity of The Social-emotional Learning Scale in Turkish form for students of secondary school. Research data collected from three different groups. First data was used for similarity between original form and translation form. High and significant correlation was found between the two forms. Second data was used for validity and reliability. Validity studies that showed Turkish form of scale was consist and it protected original form. Third data was used for testretest study reliability. Two-week test-restest study found that the acceptable reliability scores for subscales and total. As a result Socialemotional Learning scale and its subscales which task articulation, peer relations, and self-regulation can measurement social and emotional learning needs. Also scale is consist and strong in Turkish for students of secondary school.
\end{abstract}

Keywords: Social and emotional learning, social and emotional learning needs, validity and reliability.

\footnotetext{
* This article is based on the first author's doctoral dissertation in Guidance and Counseling, which was completed at the Dokuz Eylül University under the direction of the second author. Also, this study was presented on XI. National Congress of Psychological Counseling and Guidance Congress.

"Asst. Prof.Dr., Adnan Menderes University, Faculty of Education, Department of Educational Science, Guidance and Counseling, Aydın, Turkey. E-mail: tarik@dr.com

${ }^{* * *}$ Assist. Prof. Dr., Dokuz Eylül University, Faculty of Education, Department of Educational Science, Guidance and Counseling, İzmir, Turkey.
} 


\section{SUMMARY}

Purpose and Significance: Students come to schools with different personality traits. Even though schools are seen by society as education institutions, another important task of schools is to support students with different personality traits in discovering their hidden abilities. Learning happens only after the meeting of the social, emotional and physical needs of students (Elias et. al., 1997). Social and emotional learning not only helps the academic developments of students but also reinforces their positive behavior while suppressing and eliminating the negative ones (Elias et. al., 1997; Zins, Payton, Weissberg, \& Utne O'Brien, 2007). Despite this importance, measurement tools that evaluate social and emotional learning as an ability pattern or a need pattern are scarce. Hence, the objective of this study is to adapt into Turkish the Social-emotional Learning Scale developed by Coryn, Spybrook, Evergreen, \& Blinkiewicz (2009) to determine the social and emotional learning status and learning needs of primary school students. The Turkish adaptation of this scale is important since it will enable social and emotional learning to have a larger place within preventive and developmental guidance activities. In addition, the Turkish adaptation of the scale will also ensure that the handling of task articulation, peer relations and self-regulation will be handled together as social and emotional learning needs.

Method: The study has been carried out as a scale adaptation study using data obtained from three different groups. The first step of the study was language validity and a total of 61 students from Dokuz Eylül University, Buca Faculty of Education, Foreign Languages, English Teaching Department participated 24 of whom are from the third year (female $n=15$; male $n=9$ ), and 36 of which are from the fourth year (female $n=25$; male $n=11$ ). Two randomly selected classes from three different levels of three schools located at the Buca district of İzmir were also included in the study via convenience sampling method. Of the determined participants, 304 are female $(\% 50,70)$ and 296 are male $(\% 49.30)$. Sixtyfive students (female $n=34, \% 52,30$; male $n=31$ ) from the second level of a primary school at the Buca district of the city of İzmir were selected for the test-re-test reliability, which was the third part of the study. All the research groups were determined during the 2009-2010 education year using convenience sampling methods. The scale adapted in the study has been developed by Coryn et. al. (2009) and is a Likert five point scale consisting of twenty items. The scale has three sub-scales. These are task articulation, peer relations, and self-regulation. The similar scale validity of the scale has been carried out using the Social Emotional Learning scale developed by 
Kabakçı and Owen (2010). The analyses in the study have been carried out using IBM SPSS PAWS 18 (SPSS, 2009) and LISREL 8.80 (Jöreskog \& Sörbom 2006) software.

Results: In the first stage of the study, the relationships between the original and translated items have been examined using Spearman rho coefficients and significant relations between $.45-.79$ have been determined $(p<.001)$. In the second stage, significant relationships between $.57-.87$ $(p<.001)$ between the sub-scales of the scale have been determined. The examination of the three-factor structure of scale by explanatory factor analyses showed that the result were consistent with original scale form (Kaiser Meyer Olkin=.97, Bartlett's test of Sphericity $\chi_{190}^{2}=6068.37, p<.000$ ) except some items. These items found in different sub-scales to the degree that original form. However, as a result of corrective factor analysis, it has been concluded that the scale preserves its original form in the Turkish adaptation $\left(\chi^{2}=487.63, \mathrm{df}=167, \chi^{2} / \mathrm{sd}=2.92\right.$, GFI $=.92, \mathrm{NFI}=.98, \mathrm{CFI}=.99$, $\mathrm{RFI}=.98, \mathrm{IFI}=.99, \mathrm{SRMR}=.033$, RMSEA=.057). It has been determined in a similar scale study that there are significant relationships between .24-.46 between the sub-scales of the scale and the sub-scales of the Social Emotional Learning Scale. The Cronbach alpha values of the scale have been determined as .82 for task articulation, .88 for peer relation, .84 for self-regulation and .92 for the scale's total. In the third stage of the study, the test-re-test reliability has been examined and it was obtained as .80 for task articulation, .78 for peer relations, .96 for self-regulation and.93 for the total.

Discussion and Conclusions: The objective of this study was to adapt the Social-emotional Learning Scale developed by Coryn et. al. (2008) into Turkish and to apply it on the second level primary school students. As a result of the validity and reliability studies carried out, it has been concluded that second level primary school students have shown a high level of competence in evaluating the task articulation, peer relations and selfregulation skills of social and emotional learning needs along with the sum of these skills. 


\section{Sosyal-Duygusal Öğrenme Ölçeğinin Türkçe Formunun Geçerlik ve Güvenirliğinin İncelenmesi"}

\section{Tarık TOTAN*}

\author{
Zekavet KABASAKAL ${ }^{* *}$
}

ÖZ. Bu araştırmanın amacı Sosyal-Duygusal Öğrenme Ölçeğinin Türkçe formunun ortaokul düzeyinde geçerlilik ve güvenirliliğinin incelenmesidir. Araştırma üç farklı gruptan toplanan veri üzerinden yürütülmüştür. Araştırmanın birinci çalışması, ölçeğin özgün formuyla çeviri formu arasındaki benzerliği değerlendirmek amacıyla yürütülmüştür. $\mathrm{Bu}$ çalışma sonrasında ölçeğin her iki formuna ait maddeler arasında önemli ilişkiler belirlenmiştir. İkinci çalışma sonucunda ölçeğin Türkçe formunun ortaokul öğrencileri için geçerli ve güvenilir olduğu, ölçeğin özgün formunu koruduğu ve benzer bir ölçekle önemli düzeyde ilişkilendiği tespit edilmiştir. Üçüncü çalışmada iki hafta arayla ölçeğin test tekrar test güvenirliği incelenerek uygulanan ölçeğin alt boyutlarının ve toplamının kararlılık gösterdiği anlaşılmıştır. Sonuç olarak ölçeğin sosyal ve duygusal öğrenme ihtiyaçları olarakgörev bilinci, akran ilişkileri ve özdüzenlemeyi bir örüntü içinde değerlendirmede güçlü bir ölçme aracı olduğuna ulaşılmıştır.

Anahtar Sözcükler: Sosyal ve duygusal öğrenme, sosyal ve duygusal öğrenme ihtiyaçları, geçerlilik ve güvenirlilik.

\footnotetext{
* Makale birinci yazarın ikinci yazar danışmanlığında Dokuz Eylül Üniversitesi’nde Psikolojik Danışmanlık ve Rehberlik alanında tamamladığı doktora tezine dayanmaktadır. Ayrıca çalışma XI. Ulusal Psikolojik Danıșma ve Rehberlik Kongresi'nde sözel bildiri olarak sunulmuștur.

* Yrd. Doç. Dr., Adnan Menderes Üniversitesi Eğitim Fakültesi Eğitim Bilimleri Bölümü Rehberlik ve Psikolojik Danışmanlık Anabilim Aydın, Türkiye. E-posta: tarik@dr.com

** Yrd. Doç. Dr., Dokuz Eylül Üniversitesi Buca Eğitim Fakültesi Eğitim Bilimleri Bölümü Rehberlik ve Psikolojik Danışmanlık Anabilim Dalı İzmir, Türkiye.
} 


\section{GíRiş}

Sosyal ve duygusal öğrenme becerileri, sosyal ve duygusal öğrenme sürecinde kazandırılması gereken iletişim becerileri, problem çözme becerileri, kendilik değerini arttıran beceriler ve stresle başa çıkma becerilerinin birlikteliğinden oluşan temel beceriler bütünü olarak değerlendirilmektedir (Kabakçı, 2006). Sosyal ve duygusal öğrenmenin sosyal boyutu öğrencilerin akranları, öğretmenleri, aile üyeleri ve diğer bireylerle olumlu ilişkiler geliştirerek bu ilişkileri korumasını, duygusal boyutu duygular ve hissetmeler için öz-farkındalığı (self-awareness) veya benlik bilgisi (self-knowledge) beslemeyi ayrıca duyguların bilişler ve düşünceler üzerindeki etkilerini bilmeyi içermektedir (Merrell ve Gueldner, 2010). Sosyal ve duygusal öğrenme öğrencilere farkındalık, düzenleme becerileri, sosyal ilişkilerini ve duygularını tanımlayarak onları yönetme stratejilerini öğretmeyi hedefleyen kuramlar üstü bir modeldir (Elias, Zins, Weissberg, Frey, Greenberg, Haynes, Norris, Kessler, Scwab-Stone ve Shriver, 1997; Norris, 2003). Sosyal ve duygusal öğrenme ihtiyaçları ise sosyal ve duygusal ögrenme becerilerine kaynaklık eden ve bu becerileri destekleyen ihtiyaçlar olan görev bilinci, akran ilişkileri ve özdüzenlenmenin birlikteliğinden oluşan gereksinmeler bütünüdür (Coryn ve diğerleri, 2009). Sosyal ve duygusal öğrenme ihtiyaçlarıyla becerileri öğrencilere farkındalık, düzenleme becerileri, sosyal ilişkilerini ve duygularını tanımlayarak onları yönetme stratejilerini öğreterek onlara başarılı bir biçimde yaşamlarını idare etmeyi öğretmektedir (Totan, 2011).

Sosyal ve duygusal öğrenme ihtiyaçları öğrencilerin okuldaki performanslarını arttırmada etkili olduğu için öğretmenlerin sosyal ve duygusal öğrenme becerilerini geliştirmeyi bilmeleri gerekmekte, bunun içinde öğretmen yetiştirmenin temellerinde sosyal ve duygusal öğrenmeye yer verilmesi gerekmektedir (Zins, Bloodworth, Weissberg ve Walberg, 2007). Müfredat temelli yaklaşıma dayanan sosyal ve duygusal öğrenme programlarının eğitsel ve pratik öğeleri içerisinde barındırması önerilmektedir. Öyle ki okullarda öğrencilerin gerçek yaşamlarında kullanabilecekleri akılc1 ve yaratıc1 beceriler, model alabilecekleri ve modelleriyle bütünleşebilecekleri firsatlar, bulundukları etkinliklerde geribildirim alabilecekleri olanaklar ve eğitim ortamları dışında kullanabilecekleri becerileri kazandırmaya yönelik imkânlar sağlanmalıdır (Elias ve Weissberg, 2000). İlköğretim ve ortaöğretim öğrencilerinin sosyal ve duygusal öğrenme ihtiyaçlarına yönelik hazırlanan programların bilgili, sorumlu ve şefkatli bireyler olmalarına yardım edeceği vurgulanmaktadır (Elias ve Weissberg, 2000). 
Akademik becerilerin sosyal ve duygusal öğrenme becerileri ile birleşmesi öğrencilerin hedeflerini başarmalarına olanak vermektedir (Elias, 2003). Sosyal ve duygusal öğrenme öğrencilerin akademik olmayan sosyal ve duygusal gelişimlerine etki ettiği kadar, onların akademik performanslarını ve yaşam boyu öğrenmelerine de etki etmektedir (Zins ve diğerleri, 2007). Bu açıdan düşünüldüğünde sosyal ve duygusal öğrenme öğrencilerin eğitim hayatları boyunca kazanmaları gereken temel becerilere yeni standartlar getirmektedir (Elias, 2003). Ayrica sosyal ve duygusal öğrenme becerileri öğrencilerin özgür ve demokratik toplum içerisinde iyi bir vatandaş olmasına da katkı sağlamaktadır (Elias, 2009).

$\mathrm{Bu}$ araştırmanın amac1, Coryn, Spybrook, Evergreen ve Blinkiewicz'ın (2009) ortaokul düzeyindeki öğrencilerin sosyal ve duygusal öğrenme statülerini ve öğrenme ihtiyaçlarını belirlemek amacıyla geliştirdikleri, Sosyal-Duygusal Öğrenme Ölçeğini (SDÖÖ) Türkçe'ye uyarlayarak, geçerlik ve güvenirlik çalışmalarının yapılmasıdır. Ölçeğin Türkçe'ye kazandırılması önleyici ve gelişimsel rehberlik etkinliklerinde sosyal ve duygusal öğrenmenin daha fazla yer almasına olanak sağlayacağı için önem taşımaktadır. Ölçeğin Türkçe'ye kazandırılması sosyal ve duygusal öğrenme ihtiyaçları olarak görev bilinci, akran ilişkileri ve öz-düzenlemenin bir arada ele alınmasını olanak tanıyacaktır.

\section{YÖNTEM}

\section{Araştırmanın Katılımcıları}

Araştırmanın ilk basamağı olan dil geçerliği çalışmasına, 2009-2010 eğitim yılında Dokuz Eylül Üniversitesi, Buca Eğitim Fakültesi, Yabanc1 Diller Bölümü, İngilizce Öğretmenliği Anabilim Dalında öğrenci olan, 24’ü üçüncü sınıftan (kadın $n=15$; erkek $n=9$ ), 36'sı dördüncü sınıftan (kadın $n=$ 25; erkek $n=11$ ) olmak üzere toplam 61 kişi katılmıştır. Araştırmanın ikinci basağındaki katılımcı grubu SDÖÖ'nün geçerlik ve güvenirlik çalışmasının yürütülmesi amacıyla, 2009-2010 eğitim yılında İzmir ili Buca ilçesinden üç okulun üç farklı sınıf düzeyinden rastgele seçilen ikişer sınıf öğrenciyle oluşturulmuştur. Belirlenen katılımcıların 304'ü kız (\%50,70), 296's1 erkek (\%49.30) öğrencidir. Araştırma verisi toplandığı sırada, öğrencilerin 166's1 altınc1 sinıf (\%27.90), 172'si yedinci sinıf (\%28.70) ve 256'sı ise sekizinci sınıf (\%42.70) öğrencisi olarak eğitim almaktadır. Araştırmanın üçüncü çalışması olan test tekrar test uygulaması için iki hafta arayla 2009-2010 öğretim y1lında İzmir İli Buca İlçesindeki bir ortaokulunun ikinci kademesinde eğitim alan 65 öğrenciye (kız $n=34, \% 52.30$; erkek $n=31$, $\% 47.70$; altınc1 sinif $n=21, \% 31.80$; yedinci sinif $n=20, \% 30.30$; sekizinci 
Sınıf $n=24, \% 36.40)$ SDÖÖ uygulanmıştır. Araştırma gruplarının tümü 2009-2010 eğitim öğretim y1lı içerisinde olasılıksız örnekleme yöntemlerinden olan uygun örnekleme yöntemiyle belirlenmiştir.

\section{Veri Toplama Araçları}

Sosyal-Duygusal Öğrenme Ölçeği (SDÖÖ). Coryn ve diğerleri (2009) tarafindan ortaokul düzeyindeki öğrencilerin sosyal ve duygusal öğrenme statülerini ve öğrenme ihtiyaçlarını belirlemek için geliştirilen SDÖÖ kendini değerlendirme türünde yirmi maddeden oluşmaktadır. Likert tipi beşli derecelendirmeli olan ölçekte (5- Tamamen uygun, 4- Uygun, 3- Biraz uygun, 2- Çok az uygun, 1- Hiç uygun değil) Goleman, O’Brien, Wiessberg ve Zins'in çocuklardaki sosyal ve duygusal öğrenme gelişimini açıkladıkları Akademik, Sosyal ve Duygusal Öğrenme Birliği (Collaborative for Academic, Social, and Emotional Learning, [CASEL], 2009a, 2009b, 2009c) yaklaşımına dayanan üç alt boyut bulunmaktadır. Bu boyutlar; çocuğun sorumlu bir şekilde karar vermesiyle ilgili görev bilinci (task articulation), sosyal farkındalık ve sosyal ilişkilerle ilgili akran ilişkileriyle (peer relations) öz farkındalık ve öz yönetimle ilgili öz-düzenleme (self-regulation) boyutlarıdır.

Coryn ve diğerleri (2009), alanyazın taraması yoluyla oluşturdukları geniş madde havuzunu alan uzmanları, ebeveynler, öğrenciler ve araştırmacılar üzerinden yürüttükleri pilot çalışma sonrasında elde ettikleri dönütleri karşılaştırarak ölçek formunu 20 maddeye indirgemişlerdir. Ölçeğin yapı geçerliliği çalışmasında doğrulayıcı faktör analizi kullanan araştırmacılar kuramsal olarak oluşturdukları ölçme modelinin analiz sonucunda doğrulandığını bulmuşlardır $\left[\chi^{2}=520.58, \mathrm{sd}=167, \chi^{2} / \mathrm{sd}=3.12\right.$, $\mathrm{AGFI}=.90, \mathrm{CFI}=.91, \mathrm{GFI}=.92, \mathrm{NFI}=.90, \mathrm{RMSEA}=.06]$. Araştırmacılar SDÖÖ'nün güvenirlilik çalışması sonucunda görev bilinci boyutunun Cronbach alfa katsayısını .69, akran ilişkileri boyutunun alfa katsayısını .80 ve öz-düzenleme boyutunun alfa katsayısını ise .80 olarak hesaplamışlardır.

Sosyal Duygusal Öğrenme Becerileri Ölçeği (SDÖBÖ). Sosyal ve duygusal öğrenme ihtiyaçlarının sosyal ve duygusal öğrenme becerilerine kaynaklık eden temel gereksinmeler olduğu vurgulanmaktadır (Coryn ve diğerleri, 2009; Totan, 2011). Bu sebeple de SDÖÖ’nün benzer ölçek geçerliğinde SDÖBÖ kullanılmıştır. SDÖBÖ, ortaokul öğrencilerinin sosyal ve duygusal öğrenme becerilerini değerlendirmek amaciyla Kabakçı ve Owen (2010) tarafindan geliştirilmiştir. Kırk maddeden oluşan ölçek dörtlü Likert tipinde (4- Bana tamamen uygun, 3- Bana oldukça uygun, 2- Bana pek uygun değil, 1- Bana hiç uygun değil) dört alt boyuttan oluşan bir ölçme 
aracıdır. Ölçeğin alt boyutları; problem çözme becerileri ( 9 madde), iletişim becerileri (11 madde), kendilik değerini arttıran beceriler (10 madde) ve stresle başa çıkma becerileridir (10 madde). Dört alt boyutun yanı sıra ölçek toplamı alınarak da değerlendirilebilmektedir. Kabakçı ve Owen (2010), SDÖBÖ'nün betimleyici faktör analizi sonucunda toplam varyansin \%32.15'ini açılayan dört faktör ve 41 maddeden oluştuğunu bulmuştur. Doğrulayıcı faktör analizi sırasında faktör yapısıyla ilişkilenmeyen bir maddeyi ölçekten çıkarak ölçeğin kırk maddelik son halini vermişlerdir. Ölçeğin iç tutarlık çalışmasını iki farklı veri üzerinden inceleyen araştırmacılar ilk grupta ölçeğin tamamı için .88 alt ölçekler için .69-.80 arasında ikinci grupta ölçeğin tamamı için .88, alt ölçekler için .61-.83 arasında Cronbach alfa katsayılarına ulaşırken üç hafta arayla yaptıkları test tekrar test uygulaması sonucunda ise SDÖBÖ'nün toplam puanı için .85, alt ölçekler için ise .69-.82 arasında ilişkilerin var olduğunu hesaplamışlardır.

Kişisel bilgi formu. Araştırma kapsamında üç farklı gruba ait yapılan ölçümde katılımcıların cinsiyetlerini, sınıf düzeylerini ve yaşlarını belirlemek amacıyla araştırma veri formunun başında yer alan kişisel bilgi formunda iki kapalı uçlu bir açık uçlu toplamda üç soru yer almaktadır. Araştırmanın birinci ve üçüncü çalışması tekrarlı ölçüme dayandığı için bu kişisel bilgi formuna ek katılımcıların isimleri, soyadları ve okul numaraları da alınmıştır. Bu uygulamalar sırasında araştırma katılımcılarına araştırma konusunda bilgi verilmiştir.

\section{Araştırma Süreci ve Verilerin Analizi}

SDÖÖ’nün Türkçe'ye uyarlama çalışmasının yapılabilmesi için ilk olarak ölçeğin geliştiricilerinden olan Dr. Chris Coryn'le iletişime geçilerek ölçeğin uyarlanmasına yönelik gereken izin alınmıştır. İzinle birlikte ölçeğin özgün formuna ulaşılarak uyarlama çalışmasının ilk aşaması olan çeviri işlemine ve dil geçerliliği çalışmasına geçilmiştir. Ölçeğin çevirisi birbirinden bağımsız altı uzman tarafından yapılmıştır. Çeviri işlemi ardında dil geçerliği çalışmaları tamamlanarak geçerlik ve güvenirlik çalışmaları yürütülmüştür.

Araştırma kapsamında veri toplama işlemi üç farklı zamanda yapılmıştır. İlk veri toplama işlemi Dokuz Eylül Üniversitesi, Buca Eğitim Fakültesi, İngilizce Öğretmenliği alanında eğitim alan öğrencilerden gerçekleştirilirken bu işlem bir hafta arayla önce İngilizce sonra Türkçe ölçek formlarının uygulanmasıyla yapılmıştır. Öğrencilerin her iki uygulamada veri formlarına yanıt vermeleri 10-15 dakika kadar sürmüştür. İkinci veri toplama işlemi SDÖÖ’nün Türkçe formunun geçerlilik ve 
güvenirlilik çalışmasının yapılması amacıyla İzmir ili Buca ilçesindeki üç farklı okulda yürütülmüş̧ür. Öğrencilerin bu aşamadaki veri formuna yanıt vermeleri 20-25 dakika kadar sürmüştür. Üçüncü veri toplama işlemi, test tekrar test geçerliliği için iki hafta arayla İzmir ili Buca ilçesinde bulunan bir ortaokulda yürütülürken öğrencilerin veri formlarına yanıt verme süreleri her iki uygulama içinde ortalama 20-25 arasında olduğu gözlenmiştir.

Tabachnick ve Fidell (2007), araştırma verisindeki kayıp değerlerin tüm parametrelerde \%5'in üzerinde olmaması ve gözlenen kayıp değerlerin rastgele dağ 11 m göstermesi gerektiğini vurgulamaktadır. Bunun içinde araştırma verisindeki her bir parametre tek tek frekans tablolariyla incelenerek boş değerlerin \%5'in üzerinde olmadığ ve Overbay $(2004,2008)$ aykırı değerlerin araştırmacının gerçekte ulaşacağ 1 sonuçlarda çok daha farklı sonuçlara ulaşmasına neden olacağı için daima analizlerden önce aykırı değerlerin belirlenerek veriden çıkarılmasını önermektedir. Bunun için de tekli değişime ait aykırı değerler tüm parametreler için $z$-puanları alınarak \pm 3.26 standart sapma düzeyinde incelenmiş belirlenen 3 aykırı değer araştırma verisinden çıkarılmıştır. Mahalonobis $D^{2}$ yöntemi kullanılarak .001 düzeyinde çoklu değişime ait aykırı değerler (multivariate outliers) incelenmiş ve araştırma verisinde çoklu değişime ait aykırı değerlerin olmadığı gözlenmiştir. Araştırmada analizleri IBM SPSS PAWS 18 (SPSS, 2009) ve LISREL 8.80 (Jöreskog ve Sörbom, 2006) programları kullanılarak yapılmıştır. Standartlaştırılmış parametre tahminlerinde önem düzeyi .05 olarak alınmıştır.

\section{BULGULAR}

Araştırma bulguları SDÖÖ'nün dil geçerliliği, geçerlilik ile güvenirliliği ve test tekrar test geçerliliği olmak üzere üç çalışma basamağında gerçekleştirilmiştir. Her basamağa ait bulgular ayrı başlıklar altında yer almaktadır.

\section{Çalışma 1: SDÖÖ’nün Dil Geçerliği}

Ölçeğin Türkçe çevirisinde dil yeterliği bulunan Psikolojik Danışma ve Rehberlik alanıyla Psikoloji alanında çalışan altı akademisyenin çevirisine başvurulmuştur. Elde edilen çeviriler incelenerek araştırmacılar tarafından tek bir form haline getirilmiştir. SDÖÖ'nün çeviri formu daha sonra iki Türk Dili uzmanına Türkçe'deki dil ve anlam bütünlüğü açısında inceletilmiştir. İnceleme sonrasında uyarlama çalışmasında kullanılan nihai form elde edilerek dil geçerliği çalışmasında kullanılmıştır. Dil geçerliği çalışması İngilizce ve Türkçe’ye hakim İngilizce Öğretmenliği öğrencileri üzerinde 
gerçekleştirilmiştir. Dil geçerliği uygulaması sonrasında hedef ve kaynak dildeki formların arasında ölçeğin alt boyutları olan görev bilinci $(r=.79, p=$ $.000)$, akran ilişkileri $(r=.85, p=.000)$ ve öz-düzenleme $(r=.68, p=.000)$ boyutlarında pozitif yönde yüksek düzeyde anlamlı ilişkiler bulunmuştur. İngilizce ve Türkçe formlardaki maddelerin birbirileriyle olan ilişkileri ise Spearman'1n rho katsayısı kullanılarak incelenmiştir.

Tablo 1. SDÖÖ'nün Ingilizce ve Türkçe formundaki maddeler arasındaki ilişki düzeyleri

\begin{tabular}{ll}
\hline Maddeler & rho \\
\hline Madde1 & $.74^{*}$ \\
Madde2 & $.70^{*}$ \\
Madde3 & $.64^{*}$ \\
Madde4 & $.67^{*}$ \\
Madde5 & $.45^{*}$ \\
Madde6 & $.60^{*}$ \\
Madde7 & $.58^{*}$ \\
Madde8 & $.66^{*}$ \\
Madde9 & $.69^{*}$ \\
Madde10 & $.63^{*}$ \\
Madde11 & $.58^{*}$ \\
Madde12 & $.70^{*}$ \\
Madde13 & $.74^{*}$ \\
Madde14 & $.63^{*}$ \\
Madde15 & $.51^{*}$ \\
Madde16 & $.66^{*}$ \\
Madde17 & $.53^{*}$ \\
Madde18 & $.79^{*}$ \\
Madde19 & $.66^{*}$ \\
Madde20 & $.54^{*}$ \\
\hline * $\leq, 001$ &
\end{tabular}

Analiz sonucunda elde edilen ilişkiler incelendiğinde Madde5, Madde11, Madde15, Madde17, Madde18, Madde19 ve Madde20'ye ait İngilizce ve Türkçe formdaki ilişkilerin pozitif yönde orta düzeyde geride kalan tüm maddelerin ise yüksek düzey pozitif yönde önemli ilişkilere sahip olduğu bulunmuştur ( $p \leq .001)$. Dil geçerliği çalışmasında SDÖÖ'nün Türkçe formunun İngilizce formuyla üst düzeyde benzerlik gösterdiği ve dilsel yeterlik sergilediği belirlenmiştir. Bundan sonraki aşamada uyarlama çalışması sürecinde ölçeğin geçerlilik ve güvenirlilik çalışması yürütülmüştür. 


\section{Çalışma II: SDÖÖ’nün Geçerlik ve Güvenirlik Çalışması}

Uyarlama çalışmasın kapsamında yürütülen yap1 geçerliliği çalışmasının ilk ayağını BFA oluşturmuştur. BFA yapılmadan önce SDÖÖ'nün özgün formunda belirlenen faktörler üzerinden faktörler arasındaki ikili ilişkiler incelenmiştir. İkili ilişkilerin incelenmesinin nedeni özgün formda belirlenen üç boyutta faktörler sınırlandırılarak yapılacak BFA'da döndürme (rotation) yöntemi olarak hangi uygulamanın kullanılmasının belirlenmesi oluşturmuştur. Bu nedene bağlı olarak SDÖÖ boyutları arasındaki ikili ilişkileri belirmeye yönelik yapılan Pearson Momentler Çarpımı Korelasyon analizi sonucunda görev bilinci boyutu akran ilişkileriyle $.80\left(r^{2}=.64\right)$, öz-düzenlemeyle $.75\left(r^{2}=.57\right)$ ve ölçeğin toplamı olan toplam puanla da $.91\left(r^{2}=.83\right)$ düzeyinde ilişkilidir. Akran ilişkileri boyutu öz-düzenlemeyle $.78\left(r^{2}=.61\right)$, toplam puanla $.94\left(r^{2}=.89\right)$, öz-düzenleme boyutu ise toplam puanla $93\left(r^{2}=.87\right)$ düzeyinde ilişkilenmiştir (Önem düzeyi Bonferroni düzeltmesi ile .05/6=.008). Bu ikili ilişkilere ait etki büyüklüklerinin .57-.87 arasında üst düzeylerde oldukları belirlenmiştir (Field, 2005). Faktör yükleri arasında önemli ilişkilerin olması durumunda BFA'da kullanılacak döndürme tekniğinin eğik döndürme (oblique rotation) yönteminin kullanılması gerektiği için (Field, 2005; Hair, Black, Babin, Anderson ve Tatham, 2006; Tabachnick ve Fidell, 2007) SDÖÖ için BFA'da döndürme tekniği olarak eğik döndürme yöntemi kullanılmıştır. 
Tablo 2. SDÖÖ’nün BFA sonuçları

\begin{tabular}{|c|c|c|c|c|}
\hline Maddeler & $h^{2}$ & $F_{1}^{\alpha}$ & $F_{2}$ & $F_{3}$ \\
\hline Madde10 & .653 & .791 & & \\
\hline Madde7 & .618 & .784 & & \\
\hline Madde11 & .603 & .771 & & \\
\hline Madde13 & .582 & .743 & & \\
\hline Madde12 & .517 & .715 & & \\
\hline Madde9 & .511 & .711 & & \\
\hline Madde8 & .505 & .710 & & \\
\hline Madde1 & .479 & .691 & & \\
\hline Madde14 & .603 & .679 & & \\
\hline Madde17 & .453 & .660 & & \\
\hline Madde2 & .614 & & .781 & \\
\hline Madde6 & .551 & & .462 & \\
\hline Madde4 & .521 & & .451 & \\
\hline Madde3 & .412 & & .446 & \\
\hline Madde5 & .599 & & .441 & \\
\hline Madde16 & .696 & & & .744 \\
\hline Madde20 & .564 & & & .723 \\
\hline Madde15 & .647 & & & .649 \\
\hline Madde18 & .572 & & & .529 \\
\hline Madde19 & .624 & & & .496 \\
\hline
\end{tabular}

${ }^{\mathrm{a}}$ Faktör isimleri

$\mathrm{F}_{1}=$ Akran ilişkileri.

$\mathrm{F}_{2}=$ Görev bilinci.

$\mathrm{F}_{3}=$ Öz-düzenleme.

BFA bulgularına göre Kaiser Meyer Olkin değeri .97 olarak belirlenmiştir. $\mathrm{Bu}$ değerin .70 'in üzerinde olması ölçek maddelerinin faktörleşmenin yeterlik göstermesine işaret etmektedir (Leech, Barrett ve Morgan, 2005). Faktör analizinde incelenmesi gereken bir diğer kıstas olan Barlett küresellik testi değeri önemli olarak belirlenmiştir $\left(\chi_{190}^{2}=6068.37, p<\right.$ .000). Barlett küresellik testinin önemli olması faktörleşme için yeterlilik olduğuna işaret etmektedir (Field, 2005; Tabachnick ve Fidell, 2007). Eğik döndürme yöntemi kullanılarak yapılan BFA sonucunda görev bilinci boyutunun varyansın \%4.35'ini, akran ilişkileri boyutunun \%47.31'ini ve özdüzenleme boyutunun \%5'ini olmak üzere toplam açıklanan varyansın \%56.66'sının açıklandığı belirlenmiştir. Faktör ortak varyansında ölçek maddelerinin özdeğerlerinin .412-.696 arasında olduğu belirlenmiştir. Birinci faktörde genellikle özgün ölçekteki akran ilişkileri boyutuna ait maddelerin yer aldığ 1 ve bu maddelere ait faktör yüklerinin .660-.791 arasında olduğu, 
ikinci faktörde özgün formdaki maddelerden sadece Madde 1'in eksik olmasıyla birlikte (Madde 1 birinci faktörde yüklenmiştir) görev bilincinde yer alan diğer tüm maddelerin yer aldığ 1 ve bu maddelere ait faktör yüklerinin .441-.781 arasında yer aldığ 1 , son olarak da üçüncü faktörde özgün formdaki öz-düzenleme boyutuna ait maddelerde Madde 14 ve Madde 17 hariç (akran ilişkilerinde yüklenmiştir) diğer tüm maddelerin yüklendiği ve faktör yüklerinin .496-.744 arasında olduğu bulunmuştur. DFA için Çoklu Benzerlik Tahmini Yöntemi kullanılmıştır. SDÖÖ’nün özgün halinde 3 alt boyutta toplam puanı da alınabilen bir ölçektir. Bu sebeple de DFA'da öncelikle özgün formunun doğrulanma düzeyi ikinci düzeyde sınanmıştır.

Tablo 3. SDÖÖ'nün DFA'ya ait uyum iyiliği belirteçleri sonuçları

\begin{tabular}{cccccccccc}
\hline$\chi^{2}$ & sd & $\chi^{2} / \mathbf{s d}$ & GFI & NFI & CFI & RFI & IFI & SRMR & RMSEA \\
\hline 487.63 & 167 & 2.92 & .92 & .98 & .99 & .98 & .99 & .033 & .057 \\
\hline
\end{tabular}

DFA sonucunda $\chi^{2}$ değerine ait önem düzeyinin .05 düzeyinden daha düşük olduğu belirlenmiştir. Bunun içinde $\chi^{2}$ değerinin serbestlik derecesine olan oranı incelenerek, bu değerinin 2.92 olarak 3'ten daha küçük bir düzeyde olduğu hesaplanmıştır. GFI, NFI, CFI, RFI ve IFI belirteçlerine ait değerlerin .90 'dan yukarıda olduğu SRMR değerinin .05'den, RMSEA değerinin ise, 08 'den daha düşük değerlere sahip olduğu hesaplanmıştır. DFA sonucunda elde edilen çıktılar arasında modifikasyon önerileri incelendiğinde bir dizi hata kovaryansları ilişkilendirmenin $\chi^{2}$ değerinin düşmesine neden olarak modele ait uyum iyiliği belirteçlerini yükseltmede katk1 sağlayacağına yönelik öneriler olduğu görülse de ilişkilendirilmesi önerilen maddeler farklı alt ölçeklerde olduğu için -örneğin madde 13 ve madde 16- ve önerilen maddeler arasında ifadesel olarak anlam yakınlığı bulunmadığ 1 için hata kovaryanslarının ilişkilendirmesine gidilmemiştir. Sonuç olarak DFA'da elde edilen modele ait parametre tahminlerinin de yer aldığı model çıktısına ait şema aşağıda sunulmuştur. 
Şekil 1. SDÖÖ'nün ikinci düzey DFA model çıktısı

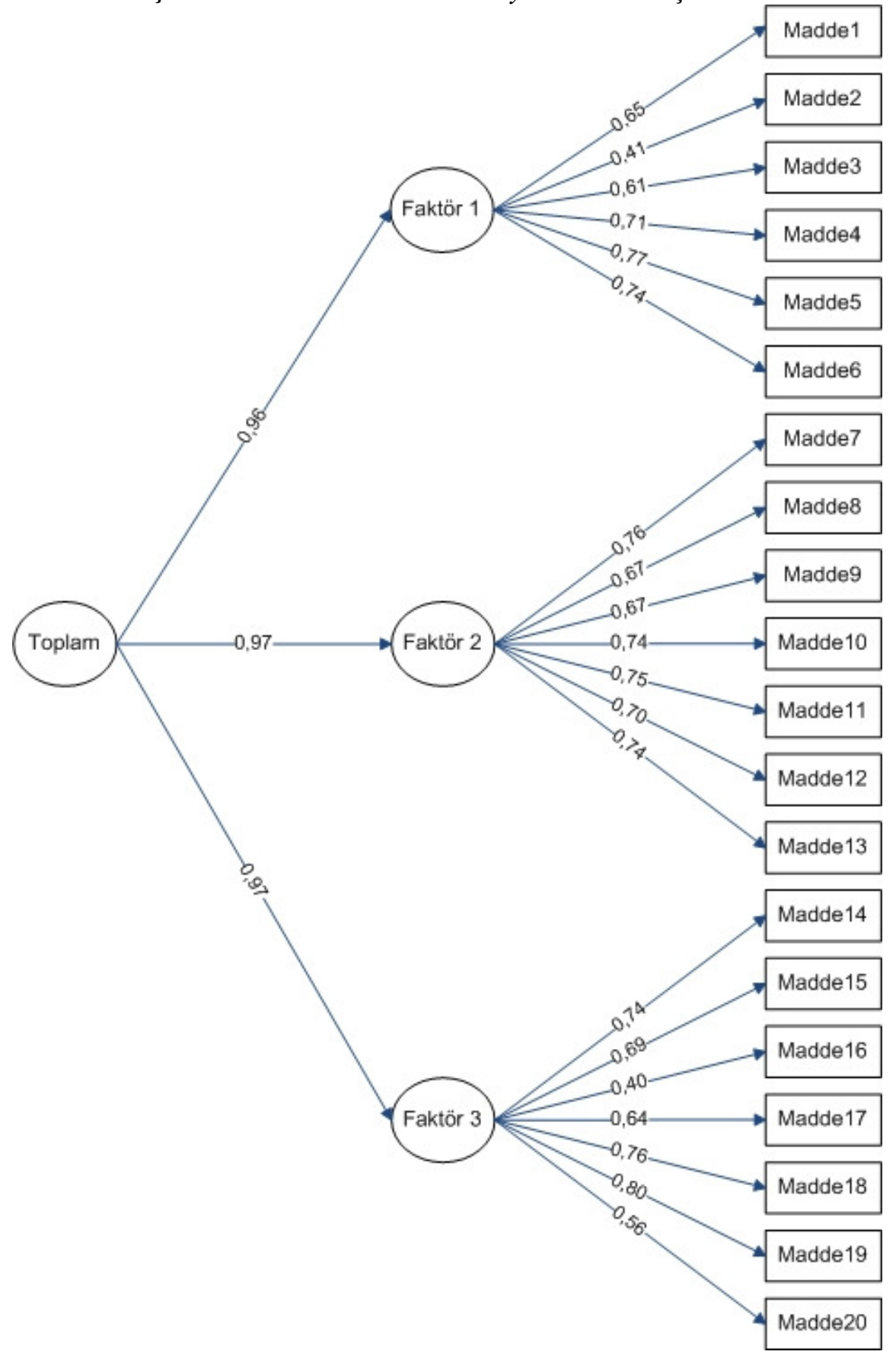


Madde hata kovaryansları arasında ilişkilendirme yapılmaksızın ikinci düzeyde sınanan model de SDÖÖ'nün maddelerine ait standartlaştırılmış parametre tahminlerine ait yüklerin $(\lambda)$ hiçbirinde negatif yüklenme olmadığı, tümünün sıfırdan büyük olduğu ve önemli birer faktör açıklayıcıları oldukları bulunmuştur. Ölçeğin alt boyutlarında görev bilinci boyutundaki standartlaştırılmış parametre tahminlerinin .41-.77 arasında, akran ilişkileri boyutunda .67-.76 arasında öz-düzenleme boyutunda ise .40.80 arasında olduğu belirlenmiştir.

\section{SDÖÖ benzer ölçek geçerliliği}

SDÖÖ’nün benzer ölçek geçerliliği Kabakçı ve Owen (2010) tarafından geliştirilen SDÖBÖ kullanılarak yapılmıştır. Benzer ölçek geçerliliği çalışması SDÖÖ'nün yapı geçerliliği çalışması için toplanan veri sırasında her iki ölçeğin birlikte katılımcılara uygulanmasıyla yürütülmüştür. Sonuçlara göre SDÖBÖ ve SDÖÖ'nün alt boyutları arasında orta düzeyde pozitif yönde ilişkilerin olduğu tespit edilmiştir. Buna göre SDÖÖ’nün alt alanlarında olan görev bilincinin SDÖBÖ’nün alt alanları iletişim becerileriyle $.38\left(r^{2}=.14\right)$, problem çözmeyle $.44\left(r^{2}=.20\right)$, stresle başa çıkmayla $.28\left(r^{2}=.08\right)$, kendilik değeriyle $.34\left(r^{2}=.12\right)$ ve SDÖBÖ'nün toplamıyla $.44\left(r^{2}=.20\right)$ düzeyinde pozitif yönde orta düzeyde önemli ilişkiler göstermektedir. SDÖÖ'nün alt alanlarında olan akran ilişkileri SDÖBÖ'nün alt alanları olan iletişim becerileriyle $.39\left(r^{2}=.15\right)$, problem çözmeyle .45 $\left(r^{2}=.21\right)$, stresle başa çıkmayla $.26\left(r^{2}=.07\right)$, kendilik değeriyle $.35\left(r^{2}=.13\right)$ ve SDÖBÖ'nün toplamıla $.44\left(r^{2}=.20\right)$ düzeyinde pozitif yönde orta düzeyde önemli ilişkiler olduğu belirlenmiştir. SDÖÖ'nün alt alanlarında olan öz-düzenlemenin SDÖBÖ'nün alt alanları olan iletişim becerileriyle .32 $\left(r^{2}=.10\right)$, problem çözmeyle $.38\left(r^{2}=.14\right)$, stresle başa çıkmayla $.24\left(r^{2}=.06\right)$, kendilik değeriyle $.30\left(r^{2}=.09\right)$ ve SDÖBÖ'nün toplamiyla $.37\left(r^{2}=.14\right)$ düzeyinde pozitif yönde orta düzeyde önemli ilişkiler sergilediği hesaplanmıştır. Son olarak da SDÖÖ’nün toplam puanın SDÖBÖ'nün alt alanları olan iletişim becerileriyle $.42\left(r^{2}=.18\right)$, problem çözmeyle .46 $\left(r^{2}=.22\right)$, stresle başa çıkmayla $.28\left(r^{2}=.08\right)$, kendilik değeriyle $.38\left(r^{2}=.14\right)$ ve SDÖBÖ’nün toplamıla $.42 \quad\left(r^{2}=.18\right)$ düzeyinde pozitif yönde orta düzeyde önemli ilişkiler olduğu bulunmuştur (Önem düzeyi Bonferroni düzeltmesi ile $.05 / 36=.002$ ). Her ne kadar ölçme araçları benzer amaçlarla geliştirilse de SDÖ yaklaşımının farklı alanlarını ölçmeye yönelik olduğu için ilişkilerin orta düzeyde çıkması kabul edilebilir olarak değerlendirilmiştir. Alt ölçeklerin kendi aralarında olan ilişkilerinin .90'ın altında kalması da ayrıca her alt ölçeğin tek başına değerlendirilebileceğini göstermektedir. Alt ölçeklerin ölçeğin toplamıyla olan yüksek düzeydeki 
ilişkileri ölçeğin tek bir boyut olarak da kullanılabileceğine güçlü bir kanıt olarak değerlendirilmiştir.

\section{SDÖÖ’nün güvenirlilik çalışması}

SDÖÖ’nün iç tutarlığına ilișkin güvenirlilik çalışması Cronbach alfa kullanılarak yapılmıştır. SDÖÖ'nün güvenirlilik çalışmasında görev bilinci için iç tutarlık katsayının .82, akran ilişkileri için .88, öz-düzenleme için .84 olarak ölçeğin toplamında ise .94 değerleri bulunmuştur.

\section{Çalışma III: Test Tekrar Test Güvenirliliği}

Araştırmanın üçüncü çalışmasını ölçeğin test tekrar test güvenirliği çalışmasi oluşturmuştur. Araştırma İzmir ili Buca ilçesindeki bir ortaokulunun ikinci kademe öğrencilerine iki hafta arayla uygulanarak yürütülmüştür. Test tekrar test analizde Pearson Momentler Çarpımı Korelasyon katsayısı kullanılmıştır. Analiz sonucunda katsayılar görev bilinci $.80(p=.000)$, akran ilişkileri $.78(p=.000)$, öz-düzenleme $.96(p=$ $.000)$ ve toplam puan için $.93(p=.000)$ olarak bulunmuştur.

\section{TARTIŞMA VE SONUÇ}

Araştırma kapsamında Coryn ve diğerlerinin (2008) geliştirildiği SDÖÖ’nün ortaokul öğrencileri üzerinden Türkçe'ye uyarlanması işlemleri yürütülmüştür. $\mathrm{Bu}$ işlemlerden ilki ölçeğin özgün formu olan İngilizceden hedef formu olan Türkçe'ye çevirisi sürecidir. Tran (2009) geçerli bir çevirinin yapılabilmesi için çeviri işleminin popülasyon ve araştırma konu alanında uygun bilgi birikimi olan uzmanlar tarafından yapılması gerektiğini belirtmektedir. Bu gibi sebeplerden dolayı birbirinden bağımsız, Psikoloji ve Psikolojik danışmanlık ve rehberlik alanı akademisyenince ölçeğin Türkçe formları oluşturularak, araştırmacılar tarafından bu formlar tek bir form haline getirilmiş, ardından da Türkçe dil bilgisi iki Türk dili uzmanı tarafindan kontrol edilmiştir. Dil geçerliliği sonucunda çeviri formla özgün formdaki maddeler arasında pozitif yönde ve önemli olarak belirlenen ilişkiler ölçeğin özgün formunu başarılı bir biçimde yansıttığına işaret olarak kabul edilmiştir.

SDÖÖ'nün yapı geçerliliği çalışmasında BFA ve DFA kullanılmıştır. DFA kullanılarak BFA'yle incelenmesi olanaksız olan kuramsal dayanaktan çıkarılan modeller incelenebilmektedir (Bandalos ve Finney, 2010; Thompson, 2005). BFA, uyarlama çalışmalarında hedef kültüre kaynak kültürde geliştirilen ölçeğin özgün halindeki faktör yapısını incelemeye firsat vermemektedir (Watkins, 1989). DFA ise ölçek geliştirme ve uyarlama çalışmalarında sıklıkla kullanılan (Levine, Hullet, Mitchell Turner ve Knight 
Lapinski, 2006), ölçüm yapısının hipotez olarak incelenen araştırmalarda uygun bir teknik olarak değerlendirilen (Goodwin, 1999) ve araştırma verisinin ölçme modeliyle uyumunu inceleme olanağ1 veren (Graham, Guthrie ve Thompson, 2003) genellikle de yap1 geçerliliği çalışmalarında BFA sonrasında kullanılması kabul gören (Worthington ve Whittaker, 2006) güçlü bir istatistiksel yöntem (Jackson, Gillaspy ve Purc-Stephenson, 2009) olarak kendini göstermektedir.

Madde ve faktör arasındaki ilişki düzeyine işaret eden (Goodwin, 1999) madde faktör yüklerinin .40 üzerinde yer alması gerektiği vurgulanmaktadır (Hair ve diğerleri, 2006). Bu durum göz önüne alındığında BFA'da SDÖÖ'deki maddelerin tümüne ait madde faktör yüklerinin .40'in üzerinde yüklendiği görülmektedir. Her ne kadar BFA sonucunda elde edilen değerler yeterlik gösterse de birinci madde özgün formunda görev bilincinde yer alırken BFA sonucunda akran ilişkilerinde yüklenmiş olması, uyarlama çalışması sırasında DFA kullanılarak ölçeğin özgün formunun Türk örnekleminde doğrulanıp doğrulanmadığının incelenmesini zorunlu kılmıştır. $\mathrm{Bu}$ sebeple ölçeğin yap1 geçerliliği çalışmasının devam eden sürecinde DFA kullanılmıştır.

Araştırmacılar $\chi^{2}$ örnekleme olan aşırı duyarlılığı tolere edebilmek için $\chi^{2}$ 'nin türevleri olan uyum iyiliği belirteçlerinin formüllerini geliştirerek iyi uyumu farkl1 kıstaslarla değerlendirmektedirler. Jöreskog ve Sörbom (1993), katılımcı sayısına olan bağımlılığın azaltılması ya da ortadan kaldırılması amaciyla uyum iyiliği belirteçlerinin geliştirildiğini belirtmektedir. Sümer (2000) $\chi^{2}$ değerinin serbestlik derecesine olan oranının üçün altında kalmasının mükemmel, beşin altında kalmasının ise orta düzeyde uyumun göstergesi olarak kabul etmektedir. GFI, NFI, RFI, CFI ve IFI belirteçleri 0'la 1 arasında değer alabilirken bu uyum iyiliği belirteçlerine ait değerlerin 0'a yaklaşması kötü 1'e yaklaşması ise iyi uyuma işaret etmektedir (Raykov ve Marcoulides, 2006; Byrne, 2010). Modelin uyumuna ait tam bir kestirim noktası tartışma konusu olmakla birlikte (Barett, 2007; Steiger, 2007) genellikle GFI, NFI, RFI, CFI ve IFI değerlerinin ,90'dan büyük olmasının uyum göstergesi olarak kabul edilmektedir (Meyers, Gamst ve Guarino, 2006; Hair ve diğerleri, 2006; Kline, 2010; Meyers, Şimşek, 2007; Tabachnick ve Fidell, 2007; Schumacker ve Lomax, 2004). RMSEA değerinin .05 'den küçük olmasının iyi uyumun ,08'den küçük olmasının kabul edilebilir ve ,08-1 arasında olmasının ise vasat uyumun işareti olarak değerlendirilmektedir (Hoe, 2008). SRMR değerinin 0-1 arasında değer aldığı ve 0 'a yaklaşan değerlerin iyi uyumu, 1'e yaklaşan değerlerin ise kötü uyumun göstergesi durumundadır (Brown, 2006). Sonuç olarak araştırmada kabul edilebilir uyum iyiliği belirteçlerine ulaşıldığı söylenebilir. 
Raines-Eudy (2000), Cronbach alfa değerinin 0-1 arasında yüklenebileceğini ve .50 üzerinde kalan değerlerinin kabul edilebileceğini belirtmekle birlikte Cronbach alfa katsayısının .70 ve üzerinde olması gerektiğini ifade eden araştırmacılar da bulunmaktadır (Morgan, Leech, Gloeckner ve Barrett, 2004; Leech, Barrett ve Morgan, 2005; Stemler ve Tsai, 2008). Alpar (2003) ise .60-.80 arasinda kalan Cronbach alfa değerlerinin ölçme aracının oldukça güvenilir, maddelerin türdeş ve aynı özelliği ölçmeye yönelik oldukları şeklinde değerlendirilebileceğini belirtmektedir. Ölçeğe ait hesaplanan tüm Cronbach alfa değerlerinin önerilen her iki değerinde üzerinde kaldığı belirlendiği için ölçeğin iç tutarlılığın yeterlilik gösterdiği saptanmıştır.

Güçlü bir güvenirlilik yöntemi olarak test tekrar test yöntemi ölçeğin cevaplayıcılarına iki hafta arayla aynı ölçeği ikinci kez uygulayarak, iki uygulama arasındaki ilişkileri belirlemeye dayanmaktadır (Rust ve Golombok, 1999; Knapp ve Mueller, 2010). Büyüköztürk (2007), iki uygulama arasındaki sürenin hedeflenen kitlenin yapısıyla değişim gösterebilmekle birlikte dört haftalık bir sürenin uygun olduğunu vurgulamaktadır. İlköğretim ikinci kademedeki öğrencilere yönelik bir ölçme aracı olmasından dolayı bu dönemdeki öğrencilerde ölçeğin iki hafta arayla uygulanmasının yerinde olacağı düşünülere test tekrar test güvenirliliği uygulaması iki hafta arayla yapılmıştır. Tavşancıl (2002) $-1,00$ ile $+1,00$ arasında değer alabilen korelasyon katsayısında $+1,00$ 'e yaklaşan değerlerin ölçüm sonuçlarına ait birlikteliğin yüksek olduğuna işaret etmekle birlikte .70'in ölçülen özelliklere ait gerçek değişkenliğin \%70'ini açıkladığını böylece rastgele hatanın sadece \%30'da kaldığını bunun içinde .70'in sınır değer olarak ele alınması gerektiğini vurgulamaktadır. Bunun içinde ölçeğin test tekrar test güvenirlilik çalışmasında elde edilen değerler doğrultusunda ölçeğin ilk ve son uygulamasının üst düzeyde birliktelik gösterdiği anlaşılmıştır.

\section{ÖNERILER}

Sonuç olarak SDÖÖ’nün Türkçe formunun özgün formuyla üst düzey benzerlik gösterdiği söylenebilir. SDÖÖ Türkiye'de yürütülecek sosyal ve duygusal öğrenme çalışmalarında kullanılabilecek niteliktedir. Bu sebeple de görev bilinci, akran ilişkileri ve öz-düzenleme gibi sosyal ve duygusal öğrenme ihtiyaçlarının birlikte değerlendirileceği çalışmalarda ölçek kullanılabileceği gibi ölçeğin alt boyutları da tek tek ele alınabilir. Sosyal ve duygusal öğrenme ihtiyaçlarını geliştirmeye yönelik yürütülecek çalışmalarla önleyici ve gelişimsel rehberlik etkinliklerini değerlendirmede ölçek kullanılabilir. İlerideki araştırmalarda diğer olası sosyal ve duygusal öğrenme ihtiyaçlarının neler olduğunu belirlemede SDÖÖ'den faydalanılabilir. 


\section{KAYNAKLAR}

Alpar, R. (2003). Uygulamalı çok değişkenli istatistiksel yöntemlere giriş 1. (2. Bask1). Ankara: Nobel Yayınevi.

Barett, P. (2007). Structural equation modelling: Adjudging model fit. Personality and Individual Differences, 42(5), 815-824.

Bandalos, D. L. ve Finney, S. J. (2010). Factor analysis. Exploratory and confirmatory. İçinde G. R. Hancock ve R. O. Mueller (Eds.). The reviewer's guide to quantitative methods in the social sciences. (syf. 93-114). New York: Taylor and Francis.

Brown, T. A. (2006). Confirmatory factor analysis for applied research. New York: The Guilford Press.

Büyüköztürk, Ş. (2007). Sosyal bilimler için veri analizi el kitabı. Ístatistik, araştırma deseni SPSS uygulamaları ve yorum. (7. Baskı). Ankara: PegemA Yayıncilik.

Byrne, B. M. (2010). Structural equation modeling with AMOS. Basic concepts, applications, and programming. (2. Bask1). New York: Routledge. Taylor \& Francis Group

Collaborative for Academic, Social, and Emotional Learning [CASEL]. (2009a). Basics, definition. What is the social and emotional learning (SEL)? Internetten 09.09.2009 tarihinde http:/www.casel.org/basics/ definition.php adresinden alınmıştır.

Collaborative for Academic, Social, and Emotional Learning [CASEL]. (2009b). About CASEL, Overview? Internetten 09.09.2009 tarihinde http://www.casel. org/ about/index.php adresinden alınmıştır.

Collaborative for Academic, Social, and Emotional Learning [CASEL]. (2009c). SEL assessment, tools, needs and out-come assessments. İnternetten 09.09.2009 tarihinde http://www.casel.org/assessment/ needs.php adresinden alınmıștır.

Coryn, C. L. S., Spybrook, J. K., Evergreen, S. D. H. ve Blinkiewicz, M. V. (2009). Development and evaluation of the Social-emotional Learning Scale. Journal of Psychoeducational Assessment, 27(3), 283-295.

Elias, M. J. (2003). Academic and social-emotional learning. Geneva: International Academy of Education and the International Bureau of Education.

Elias, M. J. (2009). Social-emotional and character development and academics as a dual focus of educational policy. Educational Policy, 23(6), 831-846.

Elias, M. J. ve Weissberg, R. P. (2000). Primary prevention: Educational approaches to enhance social and emotional learning. Journal of School Health, 70(5), 186-190.

Elias, M. J., Zins, J. E., Weissberg, R. P., Frey, K. S., Greenberg, M. T., Haynes, N. M., Norris, M., Kessler, R., Scwab-Stone, M. E. ve Shriver, T. P. (1997). Promoting social and emotional learning. Guidelines for educators. Virginia: Association for supervision and curriculum development. 
Field, A. (2005). Discovering statistics using SPSS. (2. Baskı). Londra: Sage Publications.

Goodwin, L. D. (1999). The role of factor analysis in the estimation of construct validity. Measurement in Psychical Education and Exercise Science, 3(2), 85100.

Graham, J. M., Guthrie, A. C. ve Thompson, B. (2003). Consequences of not interpreting structure coefficients in published CFA research: A reminder. Structural Equation Modeling, 10(1), 142-153.

Hair, J. F., Black, B., Babin, B., Anderson, R. E., ve Tatham, R. L. (2006). Multivariate data analysis. Upper Saddle River: Prentice Hall.

Hoe, S. L. (2008). Issues and procedures in adopting structural equation modeling technique. Journal of Applied Quantitative Methods, 3(1), 76-83.

Jackson, D. L., Gillaspy, J. A. ve Purc-Stephenson, R. (2009). Reporting practices in confirmatory factor analysis: An overview and some recommendations. Psychological Methods, 14(1), 6-23.

Jöreskog, K. G. ve Sörbom, D. (1993). LISREL 8: Structural equation modeling with the SIMPLIS command language. New York: Scientific Software International, Inc.

Kabakçı, Ö. F. (2006). İlkögrretim ikinci kademe öğrencilerinin sosyal duygusal ögrenme becerileri. Yayınlanmamış yüksek lisans tezi, Hacettepe Üniversitesi Sosyal Bilimler Enstitüsü, Ankara.

Kabakçı, Ö. M. ve Korkut Owen, F. (2010). Sosyal Duygusal Öğrenme Becerileri Ölçeği geliştirme çalışması. Eğitim ve Bilim, 35(157), 152-166.

Kline, R. B. (2010). Principles and practice of Structural Equations Modeling. (3. Bask1) New York: Guilford.

Knapp, T. R. ve Mueller, R. O. (2010). Reliability and validity of instruments. İçinde G. R. Hancock ve R. O. Mueller (Eds.). The reviewer's guide to quantitative methods in the social sciences. (syf. 337-341). New York: Taylor and Francis.

Leech, N. L., Barrett, K. C. ve Morgan, G. A. (2005). SPSS for intermediate statistics. Use and interpetation. (2. Baskı). New Jersey: Lawrence Erlbaum Associates, Inc.

Levine, T., Hullett, C. R., Mitchell Turner, M. Knight Lapinski, M. (2006). The desirability of using confirmatory factor analysis on published scales. Communication Research Reports, 23(4), 309-314.

Merrell, K. W. ve Gueldner, B. A. (2010). Social and emotional learning in the classroom: Promoting mental health and academic success. New York: The Guilford Press.

Meyers, L. S., Gamst, G. ve Guarino, A.J. (2006). Applied Multivariate Research. Design and Interpretation. California: Sage Publication Inc.

Morgan, G. A., Leech, N. L., Gloeckner, G. W. ve Barrett, K. C. (2004). SPSS for introductory statistics use and interpretation (2. Bask1). New Jersey: Lawrence Erlbaum Associates, Publishers.

Norris, J. A. (2003). Looking at classroom management through a Social and Emotional Learning lens. Theory Into Practice, 42(4), 313-318. 
Osborne, J. W. ve Overbay, A. (2004). The power of outliers (and why researchers should always check for them). Practical Assessment Research \& Evaluation, 9(6). Internetten 5.Şubat.2010 tarihinde http://pareonline.net/getvn.asp? $\mathrm{v}=9 \& \mathrm{n}=6$ adresinden alınmıştır.

Osborne, J. W. ve Overbay, A. (2008). Best practices in data cleaning: How outliers and "fringeliers" can increase error rates and decrease the quality and precision of your results. I $\square$ çinde J. W. Osborne (Ed.). Best practices in quantitative methods. (syf. 205-213). California: Sage Publications, Inc.

Raines-Eudy, R. (2000). Using structural equation modeling to test for diffenratial reliability and validity: An empirical demonstration. Structural Equation Modeling, 7(1), 124-141.

Raykov, T. ve Marcoulides, G. A. (2006). A first course in structural equation modeling. (2. Bask1). New Jersey: Lawrence Erlbaum Ass.

Rust, J. ve Golombok, S. (1999). Modern psychometrics. The science of psychological assessment (2. Bask1). Londra: Routledge.

Schumacker, R. E., ve Lomax, R. G. (2004). A Beginner's guide to structural equation modeling. New Jersey: Lawrence Erlbaum Ass.

SPSS (2009). PAWS Statistics 18 core system user's guide. Illinois: SPSS Inc.

Steinger, J. H. (2007). Understanding the limitations of global fit assessment in structural equation modeling. Personality and Individual Differences, 42(5), 893-898.

Stemler, S. E. ve Tsai, J. (2008). Best practices in interrater reliability: Three common approaches. İçinde J. W. Osborne (Ed.). Best practices in quantitative methods. (syf. 29-49). California: Sage Publications, Inc.

Sümer, N. (2000). Yapısal eşitlik modelleri. Türk Psikoloji Yazılarl, 3(6), 49-74.

Tabachnick, B. G. ve Fidell, L. S. (2007). Using multivariate statistics (5. Bask1). Boston: Allyn and Bacon.

Tavşancıl, E. (2002). Tutumların ölçülmesi ve SPSS ile veri analizi. Ankara: Nobel Yayın Dağıtım.

Tran, T. V. (2009). Developing cross-cultural measurement. New York: Oxford University Press.

Thompson, B. (2005). Exploratory and confirmatory factor analysis. Understanding concepts and applicaitons. (2. Bask1). Washington: American Psychological Association.

Totan, T. (2011). Problem çözme becerileri ĕgitim programının ilköğretim altıncı sınıf ögrencilerinin sosyal duygusal ögrrenme becerileri üzerine etkisi. Yayınlanmamış doktora tezi. Dokuz Eylül Üniversitesi Eğitim Bilimleri Enstitüsü, İzmir.

Watkins, D. (1989). The role of confiramatory factor analysis in cross-cultural research. International Journal of Psychology, 24, 685-701.

Worthington, R. W. ve Whittaker, T. A. (2006). Using exploratory and confirmatory factor analysis in scale development research: A content analysis and recommendations for best practices. The Counseling Psychologist, 34(6), 806838 . 
Zins, J. E., Bloosworth, M. R., Weissberg, R. P. ve Walberg, H. J. (2007). The scientific base linking social and emotional learning to school success. Journal of Educational and Psychological Consultation, 17(2), 191-210. doi:10.1080/ 10474410701413145

Zins, J. E., Payton, J. W., Weissberg, R. P. ve Utne O’Brien, M. (2007). Social and emotional learning for successful school performance. İçinde G. Matthews, M. Zeidner ve R. D. Roberts (Eds.). Emotional intelligence: Knows and unknowns (syf. 376-395). New York: Oxford University Press. 